\title{
Evaluation of Uterine Cavity by Hysteroscopic Examination in Infertile Women in BSMMU
}

\author{
Jesmine Banu ${ }^{1}$, Farzana Deeba ${ }^{2}$, Parveen Fatima ${ }^{3}$ Parveen Sultana ${ }^{4}$ \\ 'Associate Professor, ${ }^{2}$ Assistant Professor, ${ }^{3}$ Professor, Infertility unit, Department of Obstetrics \& Gynaecology. ${ }^{4}$ Medical Officer, Department of \\ Obstetrics \& Gynaecology, BSMMU.
}

\begin{abstract}
:
Background: Hysteroscopy is the gold standard procedure for uterine cavity exploration. However, hysteroscopy is only recommended by the WHO when clinical or complementary exams (ultrasound, HSG) suggest intrauterine abnormality or after in vitro fertilization failure. Nevertheless, many specialists feel that hysteroscopy is a more accurate tool. Objective: The aim of this prospective study is to find out the evaluation of uterine cavity by hysteroscopic examination as a primary workup of infertility. To asses the uterine pathology which is the causal factor for infertility. Method: This is a cross sectional study in which total 100 infertile patients were enrolled from infertility OPD in BSMMU with maintaining inclusion and exclusion criteria Hysteroscopy was performed with a standard sequence. The endocervical canal, uterine cavity, endometrium, and tubal ostia were inspected and findings were recorded. Results: Hysteroscopy was performed in 100 infertile women,among them $44 \%$ were presented with primary infertility and $56 \%$ presented with secondary infertility. The most common indication for diagnostic hysteroscopy was as a part of an infertility workup $80 \%$ cases. Other indication included abnormal hysterosalphingography, recurrent pregnancy loss and unexplained infertility. Hysteroscopy revealed a normal uterine cavity in 51 (51\%) women (Table 2).among them majority of patients were primary infertility.and age less than 30 years. Hysteroscopic abnormalities are significantly high in secondary than primary infertility. Conclusion: In this study abnormal hysteroscopic findings were found in $49 \%$ who underwent diagnostic hysteroscopy. Our data are an additional argument to suggest that diagnostic hysteroscopy as part of investigation in infertile woman to evaluate uterine pathology. Routine diagnostic hysteroscopy should be part of an infertility workup in both primary and secondary infertility.At the same setting therapeutic approach also be possible which is beneficial for the patients.
\end{abstract}

Keywords: Primary and secondary infertility, Diagnostic hysteroscopy, Intrauterine abnormalities.

[BSMMUJ 2016; $9(1): 32-37]$

\section{Introduction:}

Hysteroscopy is a valuable diagnostic and therapeutic modality in the management of infertility. Hysteroscopy is the gold standard procedure for uterine cavity exploration. It is widely accepted that a complete infertility workup should include an evaluation of the uterine cavity. Uterine abnormalities, congenital or acquired, are implicated as

Corresponding Author: Dr Jesmine Banu, Associate Professor Infertility unit, Department of Obstetrics \& Gynaccology, BSMMU Cell phone: 01713030721. E-mail: drjesminebanu@gmail.com one of the causes of infertility. In fact, infertility related to uterine cavity abnormalities has been estimated to be the causal factor in as many as $10 \%$ to $15 \%$ of couples seeking treatment. Moreover, abnormal uterine findings have been found in $34 \%$ to $62 \%$ of infertile women.'

Today, hysteroscopy is considered as the gold standard for evaluating the uterine cavity, and due to improved endoscopic developments, can be performed reliably and safely as an office procedure ${ }^{2}$. Direct view of the uterine 
cavity offers a significant advantage over other blind or indirect diagnostic methods. The role of hysteroscopy in infertility investigation is to detect possible intrauterine changes that could interfere with implantation or growth, or both, of the conceptus, and to evaluate the benefit of different treatment modalities in restoring a normal endometrial environment. Introduction of hysteroscopy in gynecologic practice revolutionized the diagnosis and treatment of intrauterine disease. New methodological and technological developments have made diagnostic and operative hysteroscopy much more efficient, cost effective, safe, and useful. The most common indication for hysteroscopy is abnormal uterine bleeding (AUB), but it is also used in cases of infertility and Mullerian anomalies. $^{1-2}$

Uterine factors can be found in only 2 to $3 \%$ of infertile women, but intrauterine lesions are much more common (40-50\%).These lesions can compromise spontaneous fertility as well as reduce pregnancy rates in assisted reproduction $^{3-4}$. Published observational studies suggest increased pregnancy rates after the hysteroscopic removal of endometrial polyps, submucous fibroids, uterine septum, or intrauterine adhesions, which can be found in $10 \%$ to $15 \%$ of women seeking treatment for subfertility 3. Evaluation of the uterine cavity is a basic step in female infertility workup. Classically, hysterosalpingography and transvaginal sonography are most commonly used for this purpose. Hysteroscopy, however, is considered the gold standard for diagnosis of intrauterine lesions. ${ }^{2-4}$

The benefit of the systematic use of hysteroscopy in the initial assessment of infertility remains unclear and the exploration of the uterine cavity in the initial assessment of infertility should be based on hysterosalpingography (HSG) or hysterosonography. Systematic hysteroscopy before IVF is a widely accepted practice which is supposed to improve pregnancy rates but still lacks scientific evidence. After repeated pregnancy loss, uterine cavity should be re-evaluated by hysteroscopy and this practice has been demonstrated to improve pregnancy rates..$^{3-5}$ Although there are many randomized controlled trials on technical feasibility and patient compliance demonstrating that the procedure is well tolerated and effective in the treatment of intrauterine pathologies, there is no consensus on the effectiveness of hysteroscopic surgery in improving the prognosis of unexplained subfertile women. ${ }^{6-7}$

A recent review on the effectiveness of hysteroscopy in improving pregnancy rates in subfertile women without other gynecological symptoms concluded that there is scarce evidence to support the widespread use of hysteroscopic surgery in the general subfertile population ${ }^{8-9}$. Current study was conducted with the aim to assess the role of diagnostic hysteroscopy in a primary workup of infertility by describing hysteroscopy findings.

\section{Method:}

This cross sectional study was conducted at the Infertility wing Department of Obstetrics and gynaecology Bangabandhu Sheikh Mujib Medical University (BSMMU) were studied from July 2013 to December 2014. A total of 100 infertile patients between age 20 to 40 years having abnormal uterine bleeding, unexplained infertility, abnormal HSG, Recurrent pregnancy loss were enrolled in this study by detailed history and physical examination and necessary investigations were done related to infertility. Normal Hysterosalpingogram, and pelvic infection, and cardio-respiratory disease are excluded from this study. A detailed explanation of the procedure was given by the operating surgeon, and all women signed an informed consent before undergoing the procedure. Diagnostic hysteroscopy was performed in operation theatre, using a $3 \mathrm{~mm}$ hysteroscope, under short general anaesthesia. Distention of the uterine cavity was accomplished with normal saline solution. The procedure was considered complete only when the entire uterine cavity and both tubal ostia were visualized.and different pathological findings were recorded, At the same time therapeutic approach were also be done like removal of.foreign body,polypectomy , and septoplasty.

\section{Results:}

Hysteroscopy was performed in 100 infertile women,among them $44 \%$ patients presented with primary infertility and $56 \%$ presented with secondary infertility. The most common indication for diagnostic hysteroscopy 
was as a part of an infertility workup $80 \%$ cases. Other indications included abnormal hysterosalphingography, recurrent pregnancy loss and unexplained infertility.

Hysteroscopy revealed a normal uterine cavity in 51 $(51 \%)$ women (Table 2). Majority of patients with normal hysteroscopy findings were less than 30 years of age and primary infertility.

Hysteroscopic abnormalities are significantly high in secondary than primary infertility.

Most common abnormality was Asherman syndrome followed by cervical stenosis. Other abnormalities included endometrial polyp, submucous fibroid, cervical stenosis etc At the same time therapeutic approach were also be done like Dilatation of Cervical stenosis needs $10 \% \%$ cases. Endometrial polypectomy, $7 \%$ Adhesiolysis in Asherman syndrome7\% Myomectomy5\%, removal of.foreign body, (bones, tip of MR cannula, missing CuT) $3 \%$, and septoplasty. $3 \%$

Cases. Complications of the procedure like perforation of the uterine cavity occurred in only 2 cases.

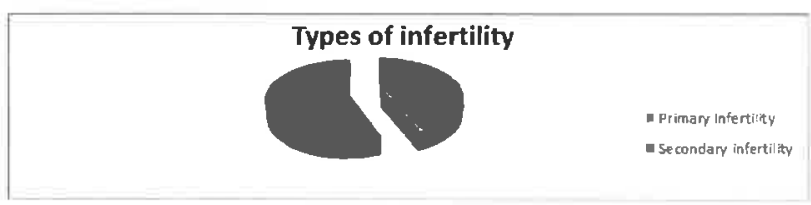

Fig- 1:

Table-I

Difference in hysteroscopic findings according to age and types of infertility

\begin{tabular}{llll}
\hline & $\begin{array}{l}\text { Normal } \\
\text { hysteros } \\
\text { copy }\end{array}$ & $\begin{array}{l}\text { Abnormality } \\
\text { in hysteros } \\
\text { copy }\end{array}$ & \\
\hline Age $<30$ years & 25 & 18 & $0.01 \mathrm{~s}$ \\
$>30$ years & 15 & 42 & \\
Primary infertility & 26 & 18 & $0.01 \mathrm{~s}$ \\
Secondary infertility & 25 & 31 & \\
\hline
\end{tabular}

\section{Table-II}

Indications for hysteroscopy in 100 infertile women

\begin{tabular}{lcl}
\hline Indication & $\begin{array}{l}\text { Primary } \\
\text { infertility } \\
\text { No. }(\%)\end{array}$ & $\begin{array}{l}\text { Secondary } \\
\text { infertility } \\
\text { No.(\%) }\end{array}$ \\
\hline As per infertility workup & $34(34 \%)$ & $46(46 \%)$ \\
Abnormal HSG & $22(22 \%)$ & $38(38 \%)$ \\
Recurrent pregnancy loss & $0(\%)$ & $10(10 \%)$ \\
Unexplained infertility & $12(12 \%)$ & $4(4 \%)$
\end{tabular}

Table-III

Abnormal hysteroscopic findings in primary and secondary infertility group.

\begin{tabular}{llll}
\hline $\begin{array}{l}\text { Hysteroscopic } \\
\text { findings }\end{array}$ & $\begin{array}{l}\text { Primary } \\
\text { infertility }\end{array}$ & $\begin{array}{l}\text { Secondary } \\
\text { infertility }\end{array}$ & Total \\
& $(\%)$ & $(\%)$ & \\
\hline Endometrial polyp & $2(2 \%)$ & $5(5 \%)$ & $7(7 \%)$ \\
Submucous fibroid & $1(1 \%)$ & $4(4 \%)$ & $5(5 \%)$ \\
Endometritis & $2(2 \%)$ & $3(3 \%)$ & $5(5 \%)$ \\
Bicomuate uterus & $2(2 \%)$ & $4(4 \%)$ & $6(6 \%)$ \\
Asherman syndrome & $4(4 \%)$ & $7(7 \%)$ & $11(11 \%)$ \\
Uterine septum & $3(3 \%)$ & $4(4 \%)$ & $2(2 \%)$ \\
Cervical stenosis & $6(6 \%)$ & $5(5 \%)$ & $10(10 \%)$ \\
Abnormal hystero- & & & \\
scopic findings & $18(18 \%)$ & $31(31 \%)$ & $49(49 \%)$ \\
Normal & $26(26 \%)$ & $25(25 \%)$ & $51(51 \%)$
\end{tabular}

\section{Table-IV}

Comparisn of Abnormal hysteroscopic findings in primary and secondary infertility group.

\begin{tabular}{lll}
\hline primary & $\begin{array}{c}\text { secondary } \\
\text { infertility group }\end{array}$ & Pvalue \\
\hline
\end{tabular}

$\begin{aligned} & \text { Abnormal hyster- } \\ & \text { oscopic finding }\end{aligned}$
$\begin{aligned} & \mathrm{N}==49 \\ & \text { Normal hyster- }\end{aligned}$
$\begin{array}{lll}\text { oscopic finding } \\ \mathrm{N}=51\end{array}$

Abnormal hysteroscopic findings are statisticaiiy significant secondary infertility group. 
Table-V

Therapeutic intervention by hysteroscopy

\begin{tabular}{|c|c|}
\hline $\begin{array}{l}\text { Hysteroscopic } \\
\text { intervention }\end{array}$ & $\begin{array}{l}\text { Primary } \\
\text { infertili infertility } \\
\text { ty }(\%) \\
(\%)\end{array}$ \\
\hline
\end{tabular}

Foreign body removal

(bones, tip of MR cannula

$\begin{array}{llll}\text { missing CuT) } & 0(0 \%) & 3(3 \%) & 3(3 \%) \\ \text { Endometrial polypectomy } & 2(2 \%) & 5(5 \%) & 7(7 \%) \\ \text { Myomectomy } & 1(1 \%) & 4(4 \%) & 5(5 \%) \\ \begin{array}{l}\text { Adhesiolysis in Asherman } \\ \text { syndrome }\end{array} & 2(2 \%) & 5(5 \%) & 7(7 \%) \\ \begin{array}{l}\text { Uterine septoplasty } \\ \text { Dilatation of Cervical }\end{array} & 1(1 \%) & 2(2 \%) & 3(3 \%) \\ \text { stenosis } & 4(4 \%) & 6(6 \%) & 10(10 \%) \\ \text { Total } & 10(10 \%) 25(25 \%) & 35(35 \%)\end{array}$

Table-VI

Comparisn of therapeutic intervention by hysteroscopy

\begin{tabular}{llll}
\hline $\begin{array}{l}\text { Hystero scopic } \\
\text { intervention }\end{array}$ & $\begin{array}{l}\text { Primary } \\
\text { infertili } \\
\text { ty }(\%)\end{array}$ & $\begin{array}{l}\text { Secondary } \\
\text { infertility } \\
(\%)\end{array}$ & Pvalue \\
\hline $\mathrm{N}=35(35 \%)$ & $10(10 \%)$ & $25(25 \%)$ & .001 \\
\hline
\end{tabular}

Therapeutic intervention by hysteroscopy was statistically significant in Secondary infertility.

\section{Discussion:}

Endometrial polyps, intrauterine adhesions, or all of these, may cause infertility by interfering with proper embryo implantation and growth.1Congenital uterine malformations are also thought to play a role in delaying natural conception.

One of the basic steps of an infertility workup is to evaluate the shape and regularity of the uterine cavity. ${ }^{6}$ Acquired uterine lesions, such as uterine fibroids, endometrial polyps, intrauterine adhesions, or all of these, may cause infertility by interfering with proper embryo implantation and growth. ${ }^{7}$ Congenital uterine malforma- tions are also thought to play a role in delaying natural conception. ${ }^{8}$

Hysteroscopy has been proved to be the definite method for evaluation of the uterine cavity and diagnosis of associated abnomalities. ${ }^{6.9}$ In the current study, secondary subfertility was more common than primary subfertility. Based on the results of the previous studies, it appears that more than $1 / 2$ of the patients interpreted as abnormal uterine cavity after diagnostic hysteroscopy, which might be a significant cause of reproductive failure. These women may be wrongly treated, or unnecessarily investigated, while their intrauterine lesion has been missed. ${ }^{6}$ And are comparable to those of the other studies reporting that normal uterine cavity was found in only $69 \%$ and $43 \%$ in primary and secondary subfertility.

In this study that normal uterine cavity was found in $26 \%$ and $25 \%$ in primary and secondary subfertility Abnomal hysteroscopic findings were more in women with secondary infertility $31 \%(31 / 100)$, compared to those with primary infertility $18 \%(18 / 100)$. Intrauterine adhesions may be due to interferences related to previous pregnancies such as MR, dilatation and curettage or previous cesarean sections. Supporting to this is the high prevalence of intrauterine adhesions, in this group, than other lesions. Also the age of the patients with abnormal hysteroscopic findings were significantly high. The findings was correlated with several studies..$^{10-11}$ No significant difference in the rate of uterine pathology was found between women with primary and secondary infertility $(22 \%$ and $38 \%$, respectively) in some study.Complications of hysteroscopy are reported in $2 \%$ of cases. These include cervical laceration and uterine perforation. Foreign body was found in 3 cases they were bones, tip of MR cannula, missing $\mathrm{CuT}$ and removal was done.

The incidence of uterine malformations in other series of infertile patients varies between $1 \%$ to $26 \%$. We observed an incidence of $11 \%$ for both primary and secondary infertility. ${ }^{9}$ Bicornuate uterus was found in $6 \%$ and uterine septum was found in 5\% case and septoplasty was done in all patient with septum. 
Endometrial polyps were diagnosed in both primary and secondary infertility groups with no statistically significant difference. The true incidence of endometrial polyps in the general population is difficult to determine, because many of them are clinically asymptomatic. Nevertheless, Shokeir found such lesions to be more frequent in the unexplained infertility population compared with fertile women. ${ }^{12}$ The possible role of these polyps in infertility is yet unclear, although follow-up on these women revealed improved reproductive outcomes after polypectomy. He concluded, in view of his results, that it seems logical to propose surgical treatment of all endometrial polyps among eumenorrheic infertile women, since even if small, they are likely to impair fertility. Removal of these polyps may enhance reproductive outcome. In the study polyp was found in $7 \%$ case and polypectomy was done in the same sitting.

Intrauterine adhesions was significantly high in secondary comparing the patients with primary infertility, as there is known relationship between secondary infertility and the existence of adhesions, being mostly the result of uterine curettage for postpartum or post abortion residua. Oliveira also found intrauterine adhesions in $10 \%$ of patients with repeated failed IVF cycles of whom none had undergone previous abortions or other uterine manipulation. He suggested that other causes of intrauterine adhesions must be ruled out. ${ }^{13,14}$

In this study intrauterine adhesion was found in $11 \%$ cases and adhesiolysis was done in 7 cases.

While debating the need for routine diagnostic hysteroscopy in the evaluation of the infertile woman, one must keep in mind that this procedure today is no longer a complicated but rather a simple, fast, outpatient procedure, requiring short training with high success rates.

Diagnostic hysteroscopy allows complete, accurate identification of intrauterine abnormalities that might negatively affect endometrial receptivity and implantation. ${ }^{15,16}$ The information derived from hysteroscopy helps the physician to institute appropriate therapy, and by doing so improve conception rates over shorter intervals. More importantly, relevant therapeutic interven- tions significantly improved the clinical pregnancy rate in those with abnonnal uterine cavity at hysteroscopy. Hysteroscopy can diagnose much more precisely, compared with HSG and even transvaginal ultrasonography, small intrauterine lesions that might affect fertility.

\section{Conclusions:}

Our results show that the incidence of uterine pathologies (congenital and acquired) in women with primary and secondary infertility approximates $49 \%$, thus, justifying, in our opinion, the use of diagnostic hysteroscopy in the primary routine investigation of infertile women suggestive of uterine pathology. Because various abnormal intrauterine pathology wa s identified by hysteroscopic examination which is the causal factor in women with primary and secondary infertility, we believe that diagnostic hysteroscopy has a similar importance in the evaluation of patients with both primary and secondary infertility.

\section{References:}

01. Brown SE, Coddington CC, Schnorr J, Toner JP, Gibbons W, Oehninger S. Evaluation of outpatient hysteroscopy, saline infusion hysterosonography and hysterosalpingography in infertile women: a prospective, randomized study. Fertil Steril 2000;74:1029-34

02. Gordts $\mathrm{S}$, Campo $\mathrm{R}$, Puttemans $\mathrm{P}$, et al. Investigation of the infertile couple. Hum Reprod 2002;17:1684-7.

03. Rowe P, Hargreave T, Mellows H, WHO Manual for the Standardized Investigation and Diagnosis of the Infertile Couple, The Press Syndicate of the University of Cambridge, Cambridge, UK, 1993.

04. de Sá Rosa e de Silva AC, Rosa e Silva JC, Cândido dos Reis FJ, Nogueira AA, Ferriani RA. Routine office hysteroscopy in the investigation of infertile couples before assisted reproduction. $\mathrm{J}$ Reprod Med 2005;50:501-6.

05. Koskas M, Mergui J, Yazbeck C, Uzan S, Nizard J. Office hysteroscopy for infertility: a series of 557 consecutive cases. Obstet Gynecol Int 2010;2010:168096

06. Shushan A, Rojansky N. Should hysteroscopy be a part of the basic infertility workup? Hum Reprod 1999;14:1923-4.

07. Brown S, Coddington C, Schnorr J, Toner J, Gibbons W, Oehninger S. Evaluation of outpatient hysteroscopy, saline infusion hysterosonography 2005;50:501-6.

08. Grimbizis GF, Camus M, Tarlatzis BS, Bontis $\mathrm{JN}$, Devroey P. Clinical implications of uterine malformations and hysteroscopic treatment results. Hum Reprod 2001;7:161-74. 
09. American Society for Reproductive Medicine Optimal evaluation of the infertile female-committee opinion. Birmingham, AL: American Society for Reproductive Medicine; 2000.50:501-6.

10. Nagele F, O'Connor H, Davies A, Badawy A, Mohamed H, Magos A. 2500 outpatient diagnostic hysteroscopies. Obstet Gynecol 1996;88:87-92

11. Pansky M, Feingold M, Sagi R, Herman A, Schneider D, Halperin R. Diagnostic hysteroscopy as a primary tool in a basic infertility workup. JSLS 2006;10:231-5.

12. Shokeir T, Shalan H, El-Shafei. Significance of endometrial polyps detected hysteroscopically in eumenorrheic infertile women. J Obstet Gynaecol Res 2004;30:84-9.

13. Oliveira FG, Abdelmassih VG, Diamond MP, Dozortsev D, Nagy
ZP, Abdelmassih R. Uterine cavity findings and hysteroscopic interventions in patients undergoing in vitro fertilization-embryo transfer who repeatedly cannot conceive. Fertil Steril 2003;80:13715.

14. Shankar M, Davidson A, Taub N, Habiba M. Randomised comparison of distension media for outpatient hysteroscopy. BJOG. 2004 Jan. 111(1):57-62.

15. Ahmad G, O'Flynn H, Attarbashi S, Duffy JM, Watson A. Pain relief for outpatient hysteroscopy. Cochrane Database Syst Rev. 2010 Nov 10. 11:CD007710.

16. Makris N, Stefanidis K, Loutradis D, Anastasiadou K, Hatjipappas $\mathrm{G}$, Antsaklis A. The incidence of retained fetal bone revealed in 2000 diagnostic hysteroscopies. JSLS. 2006 Jan-Mar. 10(1):76-7. 